\title{
Article \\ Does Resin Cement Type and Cement Preheating Influence the Marginal and Internal Fit of Lithium Disilicate Single Crowns?
}

\author{
Nourhan Samy ${ }^{1}$, Walid Al-Zordk ${ }^{1,2}{ }^{\circledR}$, Ahmed Elsherbini $^{3}$, Mutlu Özcan ${ }^{4}(\mathbb{D}$ and \\ Amal Abdelsamad Sakrana $1,2, *$ (i)
}

check for

updates

Citation: Samy, N.; Al-Zordk, W.; Elsherbini, A.; Özcan, M.; Sakrana, A.A. Does Resin Cement Type and Cement Preheating Influence the Marginal and Internal Fit of Lithium Disilicate Single Crowns? Materials 2022, 15, 424. https://doi.org/ $10.3390 / \mathrm{ma} 15020424$

Academic Editors: Bruno Chrcanovic, Javier Gil and Luca Testarelli

Received: 4 December 2021

Accepted: 4 January 2022

Published: 6 January 2022

Publisher's Note: MDPI stays neutral with regard to jurisdictional claims in published maps and institutional affiliations.

Copyright: (c) 2022 by the authors Licensee MDPI, Basel, Switzerland. This article is an open access article distributed under the terms and conditions of the Creative Commons Attribution (CC BY) license (https:// creativecommons.org/licenses/by/ $4.0 /)$.
1 Fixed Prosthodontics Department, Faculty of Dentistry, Mansoura University, Mansoura 35516, Egypt; nourhan.samy2010@gmail.com (N.S.); walidwa@gmail.com (W.A.-Z.)

2 Fixed Prosthodontics Department, Faculty of Dentistry, Horus University, Damietta 34511, Egypt

3 Mansoura General Hospital, Mansoura 35511, Egypt; dr.ahmedelsherbini6@gmail.com

4 Center for Dental and Oral Medicine, Division of Dental Biomaterials, Clinic for Reconstructive Dentistry, University of Zürich, 8032 Zürich, Switzerland; mutluozcan@hotmail.com

* Correspondence: asakrana@mans.edu.eg; Tel.: +20-102-384-9099

\begin{abstract}
This paper assesses the effect of cement type and cement preheating on the marginal and internal fit of lithium disilicate single crown. Methods: 40 maxillary premolars were selected, restored with lithium disilicate single crowns. Teeth were randomly assigned into four groups $(\mathrm{n}=10)$ based on cement type (Panavia SA or LinkForce) and preheating temperature $\left(25{ }^{\circ} \mathrm{C}\right.$ or $54{ }^{\circ} \mathrm{C}$ ). After fabrication of the restoration, cements were incubated at $25{ }^{\circ} \mathrm{C}$ or $54{ }^{\circ} \mathrm{C}$ for $24 \mathrm{~h}$, and each crown was cemented to its corresponding tooth. After $24 \mathrm{~h}$, all specimens were thermally aged to $\left(10,000\right.$ thermal cycles between $5{ }^{\circ} \mathrm{C}$ and $\left.55^{\circ} \mathrm{C}\right)$, then load cycled for 240,000 cycles. Each specimen was then sectioned in bucco-palatal direction and inspected under a stereomicroscope at $x 45$ magnification for marginal and internal fit evaluation. The data were statistically analyzed (significance at $p \leq 0.05$ level). Results: At the mid-buccal finish line, mid-buccal wall, palatal cusp, mid-palatal wall, mid-palatal finish line, and palatal margin measuring points, there was a significant difference $(p \leq 0.05)$ between the lithium disilicate group cemented with Panavia SA at $25{ }^{\circ} \mathrm{C}$ and the group cemented with LinkForce at $25^{\circ} \mathrm{C}$, while there was no significant difference $(p>0.05)$ at the other points. At all measuring points, except at the palatal cusp tip $(p=0.948)$ and palatal margin $(p=0.103)$, there was a statistically significant difference $(p \leq 0.05)$ between the lithium disilicate group cemented with Panavia SA at $54{ }^{\circ} \mathrm{C}$ and the group cemented with LinkForce at $54{ }^{\circ} \mathrm{C}$. Regardless of cement preheating, statistically significant differences were found in the buccal cusp tip, central groove, palatal cusp tip, and mid-palatal wall $(p \leq 0.05)$ in the lithium disilicate group cemented with Panavia SA at $25^{\circ} \mathrm{C}$ and $54{ }^{\circ} \mathrm{C}$, as well as the mid-palatal chamfer finish line and palatal margin in the LinkForce group cemented with Panavia SA at $25^{\circ} \mathrm{C}$ and $54{ }^{\circ} \mathrm{C}$. At the other measurement points, however, there was no significant difference $(p>0.05)$. Conclusions: The type of resin cement affects the internal and marginal fit of lithium disilicate crowns. At most measuring points, the cement preheating does not improve the internal and marginal fit of all lithium disilicate crowns.
\end{abstract}

Keywords: resin cement; preheating; marginal and internal adaptation; IPS e.max Press

\section{Introduction}

Ceramic restorations are frequently used in daily dental practice because of their superior esthetic characteristics, good mechanical properties, biocompatibility, and long-term stability [1]. For proper selection of ceramic restoration, the choice has been increasingly oriented toward lithium disilicate [2]. Lithium disilicate is classified as a glass-ceramic, in the class of particle-filled glass materials [3]. Heat-pressing or CAD/CAM processing methods are used to make lithium disilicate restorations. The mechanical characteristics of these 
restorations are influenced by the block composition and the production procedure $[4,5]$. Because of its superior esthetics, adhesive characteristics, ability to preserve tooth structure, and good fracture resistance, lithium disilicate materials have been widely promoted [6-8].

The major role of the cement is to seal the area between the restoration and prepared tooth, reduce the micro-leakage, preventing it from being loosened and dislodged [9]. To establish retention of a restoration to tooth preparation or implant abutment and maintain its integrity, dental cement should ideally meet particular biological, physical, mechanical, and handling features [10-12]. The dual-cure resin cement appears to have improved bond strength and hardness when compared to self-cure resin cement [13]. The self-adhesive resin cements were created to make the cementation step easier since these cements do not require the tooth to be conditioned or the restoration to be pre-treated [14]. Selfadhesive resin cements have a high viscosity, which can rapidly increase after an acid-base reaction [15].

Residual monomers and unreacted photo-initiators from incomplete monomer conversions can leak into the oral cavity, resulting in allergic responses and bacterial build-up around the restorations [16]. Because the mechanical properties and polymerization kinetics of polymers are altered by the heat degree, it was advised to warm-up refrigerator-stored resin cements to at least room temperature before clinical use and pre-heating to $60^{\circ} \mathrm{C}$ to reinforce the bonding potential of the tested resin cement $[17,18]$. Increased temperature during polymerization of dual-cure resin cements raised the degree of conversion, according to a study that investigated the influence of temperature on the degree of conversion and working duration of dual-cured resin cements exposed to varied curing conditions [19].

An essential measurement for evaluating restorative fit is the fit discrepancy between the interior surface of the restoration and the prepared tooth [20-23]. Gingival health is ensured by the good marginal fit of the restoration, which results in less cement dissolution, decreases the possibility of discoloration, and reduced the potential of recurrent caries [24]. Internal fit enhances mechanical qualities such as retention and fracture resistance, whereas poor internal fit can result in compromised retention and weakening of the restored tooth [25-27]. Many factors influence the marginal and internal fit, including the ceramic type, cement type, geometry of tooth preparation, material handling, curing method, and the procedure employed to remove excess cement [28]. The fit of a restoration could be verified and evaluated by many methods such as direct viewing of the margin, cross-sectioning, and replica technique [29,30]. Therefore, the purpose of this investigation was to assess the influence of adhesive cement type and cement preheating on the fit of lithium disilicate single crowns. The first null hypothesis was that the type of resin cement will not affect the fit of lithium disilicate crowns. The second null hypothesis was that the pre-heating of adhesive resin cement will not affect the fit of lithium disilicate crowns.

\section{Materials and Methods}

Forty sound maxillary premolars teeth of comparable dimensions, extracted for orthodontic purposes, were collected for this in vitro study. These teeth were examined under proper lightening to ensure there freed from caries, cracks and, fractures. Teeth were disinfected in sodium hypochlorite solution bleach (Clorox Bleach, Clorox Egypt CO., Cairo, Egypt) for one week [30]. To avoid dehydration, teeth were kept in standardized saline solution (Sodium Chloride BP 0.9 percent, Fibco, Alexandria, Egypt) at room temperature until use. The included teeth dimensions, as measured using a digital caliper (150 mm/6 in, American spares, Colorado Springs, CO, USA), were $5.5 \pm 0.5 \mathrm{~mm}$ occluso-cervical, $7 \pm 0.5 \mathrm{~mm}$ mesio-distal, and $9 \pm 0.5 \mathrm{~mm}$ bucco-palatal. Table 1 shows how the teeth were classified into four groups based on the type of resin cement used (either Panavia SA cement plus or G-Cem LinkForce cement) and cement preheating (either at $54^{\circ} \mathrm{C}$ or $25^{\circ} \mathrm{C}$ ). 
Table 1. The study groups.

\begin{tabular}{cc}
\hline Group & Code \\
\hline Restoration cemented using Panavia SA at $25^{\circ} \mathrm{C}$ & PR \\
Restoration cemented using Panavia SA at $54^{\circ} \mathrm{C}$ & PH \\
Restoration cemented using LinkForce at $25^{\circ} \mathrm{C}$ & LR \\
Restoration cemented using LinkForce at $54^{\circ} \mathrm{C}$ & LH \\
\hline
\end{tabular}

Prior to tooth preparation, a putty index was made for each tooth using a vinyl polysiloxane impression material (Imflex Putty, Meta Biomed Co., Cheongju-si, Korea). CAD-CAM technology was used for teeth preparation to control tooth reduction [31]. Each tooth was prepared using a high-speed handpiece and a dental surveyor (Dentalfarm A3006 B manual surveyor, Turin, Italy) with preparation dimensions corresponding to the lithium disilicate restorative material (1 mm chamfer margin, $2 \mathrm{~mm}$ palatal cup reduction, $1.5 \mathrm{~mm}$ buccal cusp reduction and 6-degree axial wall taper). The amount of tooth reduction was evaluated using the pre-preparation putty index (Figure 1).
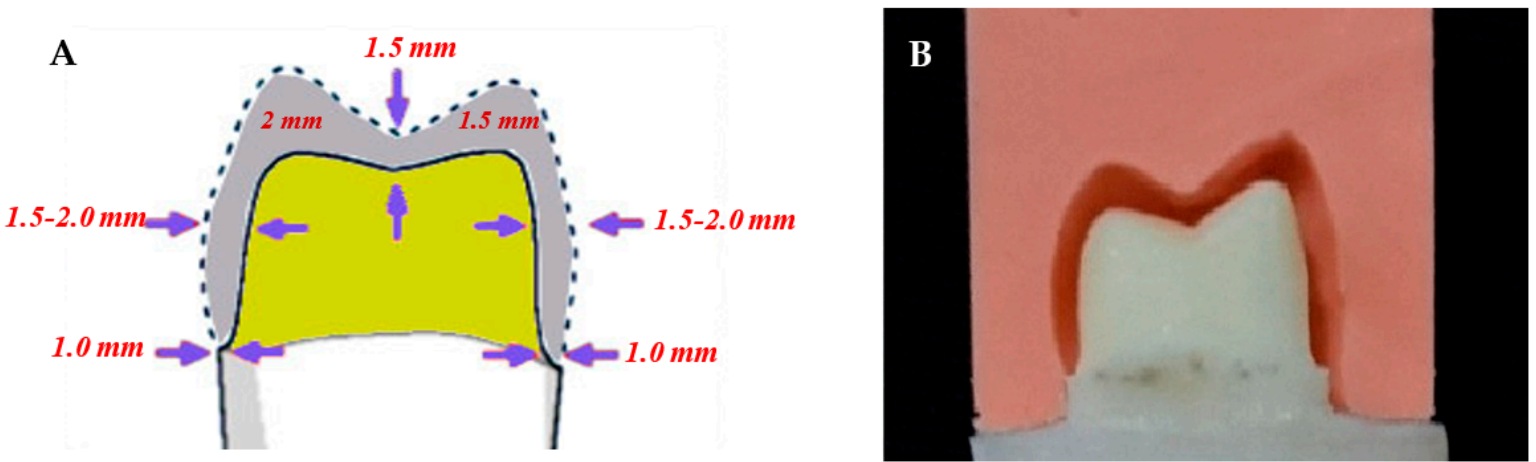

Figure 1. (A) Illustration of tooth preparation for lithium disilicate crown; (B) Proximal view for prepared tooth inside the putty index.

Each tooth was scanned using the CAD-CAM scanner (ceramill Map 400 optical scanner, Amann Girrbach $\mathrm{GmbH}$, Koblach, Austria) after being coated with anti-reflection scan powder (Telescan white, DFS Diamon GmbH, Riedenburg, The Netherlands). The crown design was created with CAD-CAM software (Ceramill Mind, Amann Girrbach $\mathrm{GmbH}$, Koblach, Austria) and an 80- $\mathrm{mm}$ cement space was chosen, after which a pattern was 3D printed (Phrozen shuffle, phrozen Technology, Hsinchu, Taiwan) using a printer resin (FTD Dentifix-3D LR, 3D printing resin, Lumi industries, Montebelluna, Italy). The resin patterns were sprued and invested, then the pressing procedures were performed following the instructions of the manufacture using a lithium disilicate ingots (IPS e.max Press, Ivoclar Vivadent, Schaan, Liechtenstein). Then, each crown was finished and cleaned before being subjected to crystallization and glaze firing following the instructions of the manufacture.

For bonding, the intaglio surfaces of the crowns were etched ( $9 \%$ Porcelain etch, Ultradent, South Jordan, UT, USA) for $20 \mathrm{~s}$. The resin cements were preheated $\left(25{ }^{\circ} \mathrm{C}, 54{ }^{\circ} \mathrm{C}\right)$ using an incubator (Series BD model 56, Standard Incubators, BINDER GmbH, Tuttlingen, Germany). The abutments in the LR and LH groups were pre-treated with the bonding agent (G-Premio BOND, GC Corp., Tokyo, Japan) for $15 \mathrm{~s}$ before being light-cured (LED curing light, Guilin Woodpecker Medical Instrument Co., Guilin, China) for 20 s. The corresponding resin cement was dispensed in the intaglio surface of each crown for all specimens. The crown was then mounted on its corresponding tooth and held under a load of $10 \mathrm{~N}$ throughout polymerization (Instron Universal testing machine, 3345, Norwood, MA, USA) [32]. To enable the removal of excess cement, an initial light curing for $3 \mathrm{~s}$ was conducted, then the final curing was done for $20 \mathrm{~s}$ on each side, according to the manufacturer's recommendations. 
Thermal aging (Thermo-cycler SD Mechatronic GmbH, Munich, Germany) was performed on all specimens for 10,000 cycles $\left(5^{\circ} \mathrm{C} / 55^{\circ} \mathrm{C}\right)$. Then, all specimens were subjected to 240,000 load cycles (chewing simulator CS4.4, SD Mechatronic GmbH, Munich, Germany) with $50-\mathrm{N}$ load at $60 \mathrm{~mm} / \mathrm{s}$ [33].

All the specimens were sectioned centrally from the buccal to palatal direction into two sections. Linear precision cutting micro-saw (Isomet 4000 linear cutting microsaw, Buehler, Germany) was used.

Measurement of marginal and internal fit: The cut sections were examined under a stereomicroscope (Olympus SZ 61, Tokyo, Japan) at 45 magnification to measure the marginal and internal fit at nine locations (buccal margin, mid-buccal finish line, midbuccal axial wall, buccal cusp tip, central groove, palatal cusp tip, mid-palatal axial wall, mid-palatal finish line, palatal margin) as shown in Figure 2. Then the measurements data were tabulated and statistically analyzed.

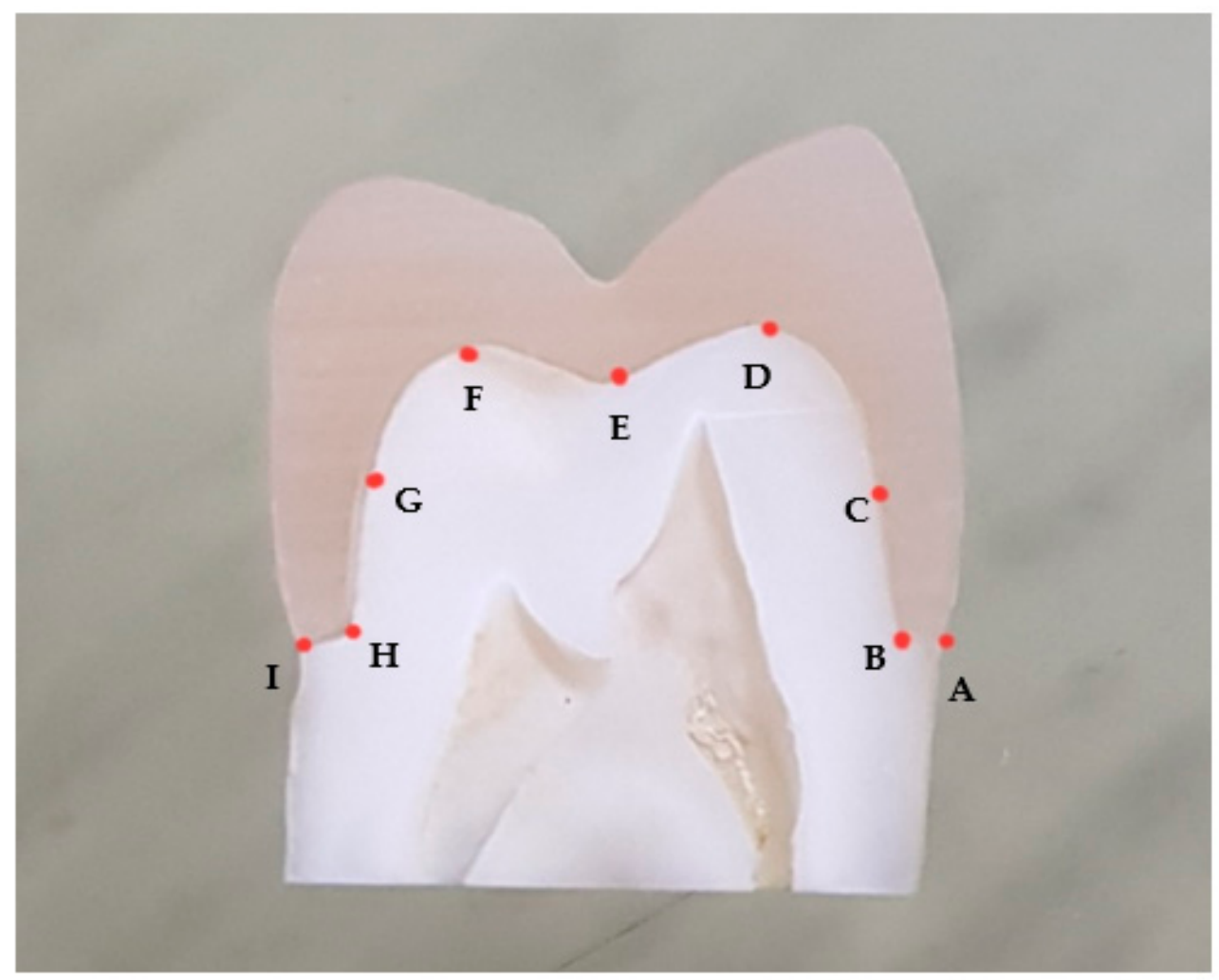

Figure 2. Points of measurement of marginal and internal fit; (A) buccal margin, (B) buccal chamber finish line, (C) mid-buccal axial wall, (D) Buccal cusp tip, (E) central groove, (F) palatal cusp tip, (G) mid-palatal axial wall, (H) palatal chamfer finish line, (I) palatal margin.

Data were analyzed a software (SPSS V 22.0, IBM SPSS corp., Armonk, NY, USA). The normality of data was checked using the Shapiro-Wilk test. A two-way ANOVA test was performed to detect the effect of the two independent variables and Student's $t$-test was used to compare two independent groups.

\section{Results}

There was a statistically significant difference between lithium disilicate crowns cemented with Panavia SA cement at $25^{\circ} \mathrm{C}$ and that preheated at $54{ }^{\circ} \mathrm{C}$ at the buccal margin $(\mathrm{t}=2.69, p=0.02)$, buccal cusp tip $(\mathrm{t}=2.77, p=0.013)$, central groove $(\mathrm{t}=3.45, p=0.003)$, palatal cusp tip $(\mathrm{t}=4.91, p<0.001)$, and mid-palatal axial wall $(\mathrm{t}=6.38, p<0.001)$; however, no significant differences at other points of measurement. Additionally, there was a significant difference between lithium disilicate groups cemented with LinkForce cement at $25{ }^{\circ} \mathrm{C}$ and that cemented with LinkForce cement preheated at $54{ }^{\circ} \mathrm{C}$ at all points of measurement 
except at the buccal margin $(\mathrm{t}=1.69, p=0.107)$, buccal finish line $(\mathrm{t}=0.958, p=0.351)$, and mid-buccal axial wall $(\mathrm{t}=0.253, p=0.803)$.

There was a statistically significant difference between lithium disilicate crowns cemented with Panavia SA cement at $25^{\circ} \mathrm{C}$ and LinkForce cement at $25^{\circ} \mathrm{C}$ at all measurement points except at the buccal margin $(t=1.43, p=0.171)$ and central groove $(t=1.55, p=0.138)$. In addition, there was a significant difference between lithium disilicate crowns cemented with Panavia SA cement preheated at $54{ }^{\circ} \mathrm{C}$ and LinkForce cement preheated at $54{ }^{\circ} \mathrm{C}$ except at the palatal margin $(t=1.72, p=0.103)$ and palatal cusp tip $(t=0.07, p=0.948)$. Table 2 .

Table 2. Means and standard deviations of the marginal and internal fit $(\mu \mathrm{m})$ of the studied groups.

\begin{tabular}{ccccc}
\hline \multirow{2}{*}{ Points of Measurements } & \multicolumn{2}{c}{ Panavia SA Cement } & \multicolumn{2}{c}{ LinkForce Cement } \\
\cline { 2 - 5 } & $\mathbf{2 5} \mathbf{~}^{\circ} \mathbf{C}$ & $\mathbf{5 4}{ }^{\circ} \mathbf{C}$ & $\mathbf{2 5}^{\circ} \mathbf{C}$ & $\mathbf{5 4}^{\circ} \mathbf{C}$ \\
\hline Buccal margin & $107.10 \pm 26.15^{\mathrm{A}}$ & $79.9 \pm 18.38^{\mathrm{B}}$ & $122.90 \pm 23.35^{\mathrm{B}, \mathrm{C}}$ & $149.30 \pm 43.26^{\mathrm{A}, \mathrm{C}}$ \\
\hline Mid-buccal chamfer & $106.5 \pm 16.34^{\mathrm{A}}$ & $104.70 \pm 19.71$ & $129 \pm 22.69^{\mathrm{B}}$ & $141 \pm 32.47^{\mathrm{A}, \mathrm{B}}$ \\
\hline Mid-buccal axial & $109.20 \pm 13.07^{\mathrm{A}, \mathrm{B}}$ & $119.20 \pm 20.69^{\mathrm{A}, \mathrm{C}}$ & $152.40 \pm 28.65^{\mathrm{C}, \mathrm{D}}$ & $149.20 \pm 27.96^{\mathrm{B}, \mathrm{D}}$ \\
\hline Buccal cusp tip & $126.50 \pm 24.50^{\mathrm{A}, \mathrm{B}}$ & $151.50 \pm 14.73^{\mathrm{C}}$ & $131.40 \pm 15.32^{\mathrm{A}, \mathrm{D}}$ & $273.10 \pm 14.20^{\mathrm{B}, \mathrm{C}, \mathrm{D}}$ \\
\hline Central groove & $227.0 \pm 40.84^{\mathrm{A}, \mathrm{B}}$ & $177 \pm 20.72^{\mathrm{C}}$ & $204.40 \pm 21.17^{\mathrm{A}, \mathrm{D}}$ & $286 \pm 18.98^{\mathrm{B}, \mathrm{C}, \mathrm{D}}$ \\
\hline Palatal cusp tip & $147.90 \pm 26.48^{\mathrm{A}, \mathrm{B}}$ & $210.30 \pm 30.23^{\mathrm{C}, \mathrm{D}}$ & $108.90 \pm 10.21^{\mathrm{A}, \mathrm{C}}$ & $208.60 \pm 76.02^{\mathrm{B}, \mathrm{D}}$ \\
\hline Mid-palatal axial & $195.90 \pm 43.7^{\mathrm{A}, \mathrm{B}}$ & $103.50 \pm 13.55^{\mathrm{A}, \mathrm{C}}$ & $112.10 \pm 20.29^{\mathrm{B}, \mathrm{D}}$ & $197.10 \pm 42.45^{\mathrm{C}, \mathrm{D}}$ \\
\hline Mid-palatal chamfer & $109.5 \pm 8.96^{\mathrm{A}, \mathrm{B}}$ & $121.50 \pm 19.01^{\mathrm{A}, \mathrm{C}}$ & $140 \pm 25.49^{\mathrm{D}}$ & $202 \pm 18.14^{\mathrm{B}, \mathrm{C}, \mathrm{D}}$ \\
\hline Palatal margin & $157.70 \pm 51.05^{\mathrm{A}}$ & $120.90 \pm 28.99^{\mathrm{A}, \mathrm{B}}$ & $92.90 \pm 21.98^{2}$ & $148.80 \pm 42.43^{\mathrm{B}}$ \\
\hline
\end{tabular}

Note: Means with similar superscripted letters in the same row denote significant difference between groups by post hoc Tukey test.

The two-way ANOVA test revealed that there was a statistically significant combined effect of changing cement type and cement preheating on buccal margin (with 40.4\%), buccal cusp tip (with 92.1\%), central groove (with 68.7\%), mid palatal axial wall (with $64.3 \%$ ), mid palatal finish line (with $78.2 \%$ ), palatal margin (with $27.8 \%$ ) of each point is affected by these factors. A representative stereomicroscopic images of marginal and internal fit of specimens are shown in Figures 3-6.

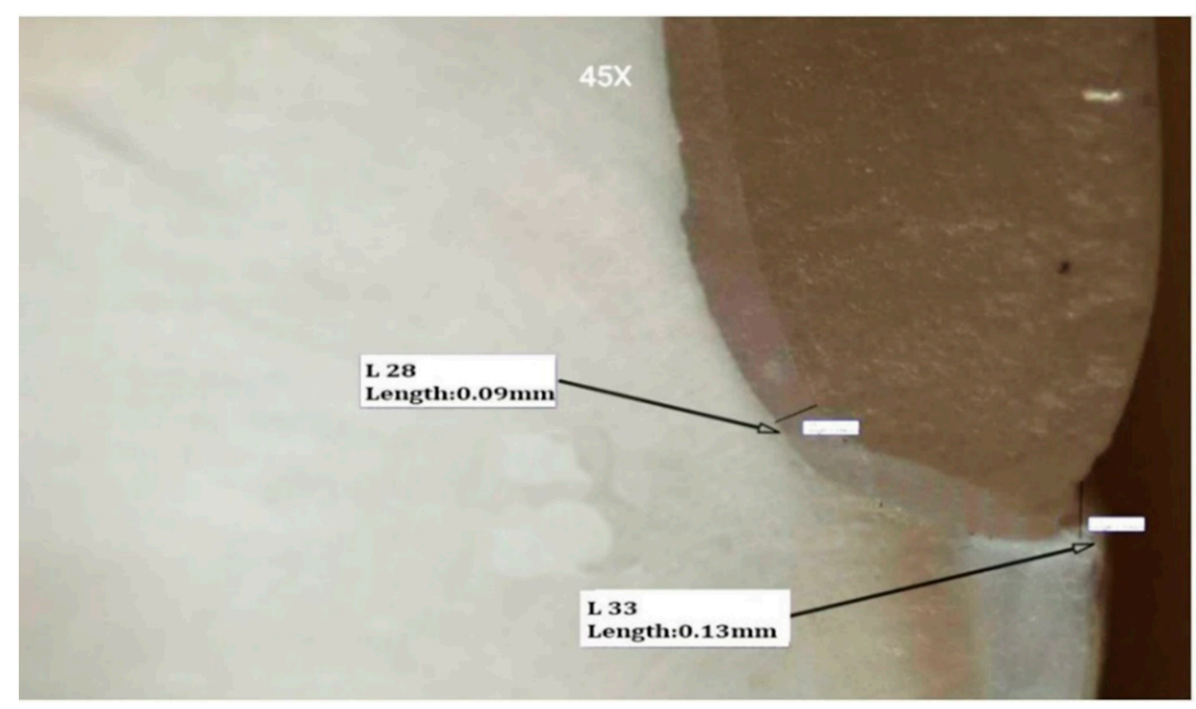

Figure 3. Stereomicroscopic view (45X) represents marginal and internal fit of a sectioned specimen at buccal margin and buccal finish line. 


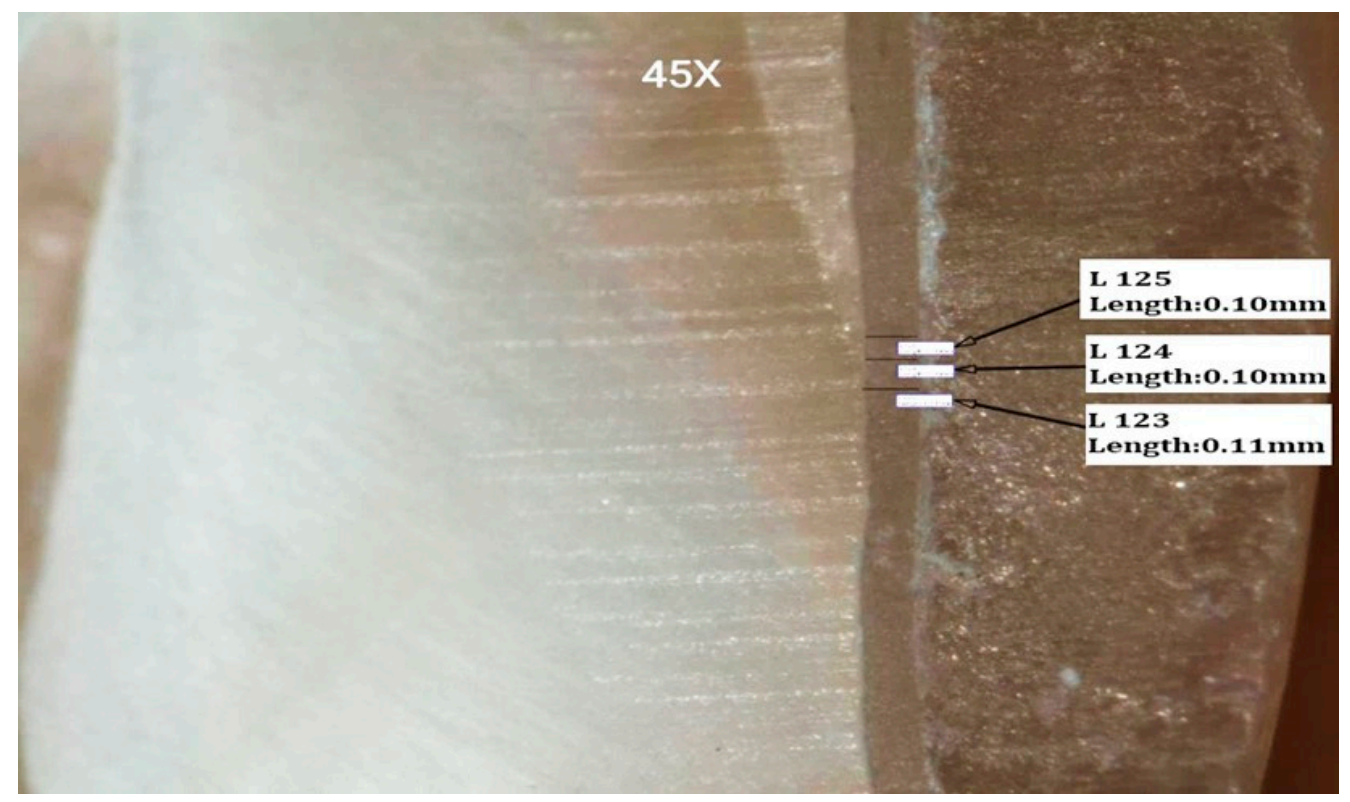

Figure 4. Stereomicroscopic view (45X) represents marginal and internal fit of a sectioned specimen at mid buccal axial wall.

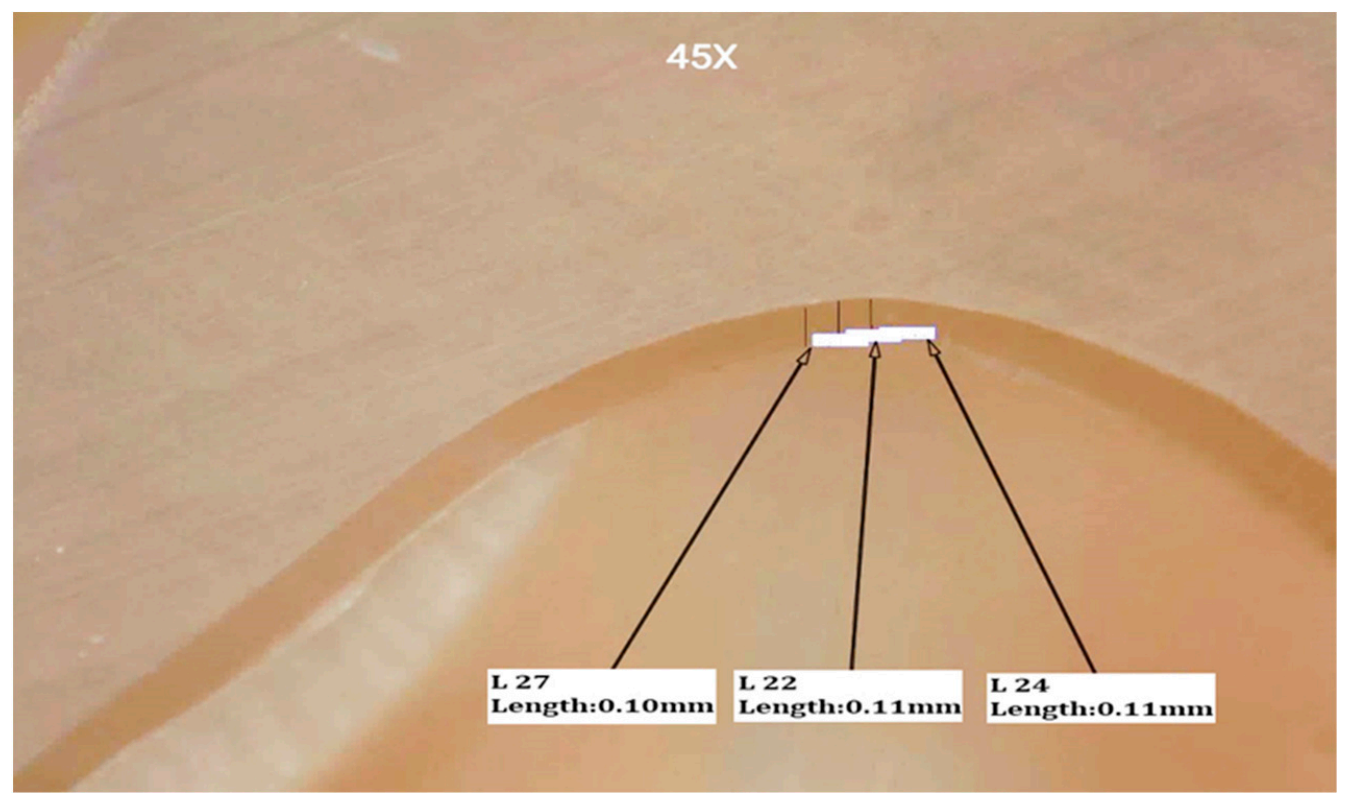

Figure 5. Stereomicroscopic view (45X) represents marginal and internal fit of a sectioned specimen at buccal cusp tip. 


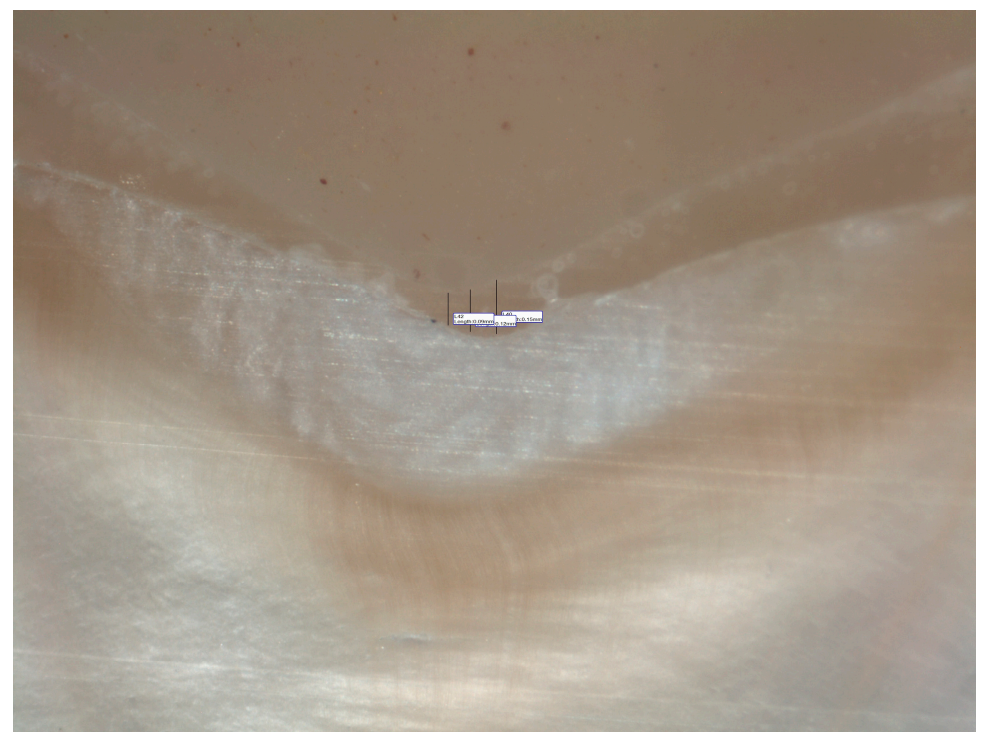

Figure 6. Stereomicroscopic view (45X) represents marginal and internal fit of a sectioned specimen at central groove.

\section{Discussion}

The aim of this study was to evaluate the influence of resin cement type and preheating on the marginal and internal fit of lithium disilicate restoration. Both tested hypotheses were rejected as the results revealed that the resin cement type and cement preheating significantly affects the marginal and internal fit of lithium disilicate single crowns.

The maxillary first premolars were chosen for the present study, with special attention made to the selection of teeth with comparable sizes [34]. Dual-cured resin cements are suitable for the cementation of ceramic restorations because of the combined benefits of both light and chemical cure mechanisms to ensure adequate and complete polymerization of the material even when light activation is insufficient [35]. An effective polymerization process can achieve a higher degree of monomer conversion in resin materials [36]. However, polymerization stress represents a concern with the use of dual-cured resin cements. Delaying the start of light curing (the time from the start of cement mixing and seating of the restoration) could lead to a reduction in these polymerization stresses [37]. In the current study, a short initial light cure was performed to facilitate removal of excess cement, then the final curing was performed. However, the tack-curing may interfere with the polymerization. Other studies found that the initial light curing had no influence on the mechanical properties of the cement [38,39]. Furthermore, in our investigation, preheating resin cement to $54^{\circ} \mathrm{C}$ was chosen because previous studies suggested that preheating to $55-60{ }^{\circ} \mathrm{C}$ could induce pulp damage and breakdown in some types of resin cement [17-19].

Because it has a better vertical marginal gap than its comparable CAD-CAM materials, pressable lithium disilicate was chosen [40]. A study compared the marginal fit of lithium disilicate crowns generated using the hot-press technique to those fabricated by the CAD$\mathrm{CAM}$ approach and concluded that the pressed restorations produce improved marginal fit compared to the CAD/CAM restorations [2].

Standardized tooth preparation was done utilizing CAD-CAM technology for increased control over tooth preparation, which offers numerous advantages over hand fabricated models [41]. Clinical variables influencing the marginal fit of ceramic restorations include tooth preparation geometry, type of finish line, cement type, and ceramic manufacturing technique and material [42].

Artificial ageing is an experimental strategy for determining the clinical behavior of a restorative material by simulating oral environmental circumstances extra-orally [43]. With thermal aging, repeated stresses induce of contraction and expansion, resulting in the propagation of cracks and fractures, loss of retention, the creation of cracks at interfaces, 
and degradation [44]. In addition, the applied aging may alter the marginal and internal fit, as reported by Dessouky et al. [45], who found that artificial aging increases the vertical marginal discrepancy by thermo-mechanical stress.

The cross-sectioning technique was adopted in this work to allow direct measurement of the internal and marginal adaption in both vertical and horizontal planes under the microscope, reducing the possibility of repositioning errors. Several studies employed the cross-sectioning methodology to assess fit precision and found it to be more reliable than other methods [46]. However, some data may be lost during sectioning procedures as a result of this technique [30]. Additionally, micro-computed tomography provides excellent non-destructive tool for analysis of the internal and marginal adaption [47].

The results of the current study revealed a statistically significant effect of preheated cements on the marginal and internal fit of lithium disilicate crowns. This is in line with a prior work by Elsayed [48], which discovered that preheated resin composites increase adaptability and reduce interfacial gaps. Aygun et al. [49] also found that preheating the self-adhesive G-Cem cement to $37^{\circ} \mathrm{C}$ improved marginal adaption compared to the application at $25^{\circ} \mathrm{C}$ and $54^{\circ} \mathrm{C}$. Restorations cemented using etch-rinse cement (Variolink $\mathrm{N}$ high viscosity cement) mixed at $25^{\circ} \mathrm{C}, 54^{\circ} \mathrm{C}$, and $37^{\circ} \mathrm{C}$ performed better clinically than those cemented with self-adhesive G-Cem at the same temperatures.

Two types of resin cements were employed in the current study: Panavia SA Cement Plus self-adhesive resin cement and G-CEM LinkForce adhesive resin cement. On the marginal and internal fit of lithium disilicate crowns, there was a considerable difference between the utilized cements. This finding is partially in line with Raafat [50], who looked into the influence of CAD/CAM restorations, heat-press technique, and resin cement type on the marginal and internal adaptation of all ceramic IPS e.max crowns. The solubility of the cement used plays an important role in providing better restoration fit [51]. Because the insoluble resin cement absorbs water, it may aid in the relaxation of internal tensions induced by polymerization shrinkage, lowering the risk of inter-facial failure during thermocycling [52].

The current study found that cement type and cement preheating had a substantial effect on specific points of measurement among the analyzed groups, but not on other points of measurement. This could be due to what is known as the overshoot phenomenon. Overshoot phenomena, which replicate virtual peaks on the borders, might cause internal gaps to widen at particular spots [53].

As a limitation of this study, only one type of ceramic materials was used with only two types of resin cements. The differences in the selected natural teeth, since it was difficult to select a perfect match for all selected teeth. This study was performed to simulate limited period in the oral environment. Cross-sectioning technique was used in a destructive method. Thus, other technique as micro-computed tomography which provides a nondestructive tool for analysis of the adaption is required. Clinical studies are needed to test the effectiveness of preheating on the clinical performance of full-coverage restorations.

\section{Conclusions}

The type of resin cement affects the internal and marginal fit of lithium disilicate crowns. At most measuring points, the cement preheating does not improve the internal and marginal fit of all lithium disilicate crowns.

Author Contributions: Conceptualization, W.A.-Z. and A.A.S.; methodology, N.S. and W.A.-Z.; software, W.A.-Z., A.E. and A.A.S.; validation, W.A.-Z., M.Ö., A.E. and A.A.S.; formal analysis, W.A.-Z. and A.A.S.; investigation, N.S., W.A.-Z. and A.A.S.; resources, N.S.; data curation, N.S. and A.A.S.; writing-original draft preparation, N.S. and W.A.-Z.; writing-review and editing, N.S., W.A.-Z., M.Ö. and A.A.S.; visualization, W.A.-Z., A.E. and A.A.S.; supervision, W.A.-Z. and A.A.S.; project administration, N.S., W.A.-Z. and A.A.S.; funding acquisition, N.S. and M.Ö. All authors have read and agreed to the published version of the manuscript.

Funding: This research received no external funding. 
Institutional Review Board Statement: The study was conducted according to the guidelines of the Declaration of Helsinki, and approved by the Ethics Committee, Faculty of Dentistry, Mansoura University (protocol codeA11120219 and 12 February 2019).

Informed Consent Statement: Not applicable.

Data Availability Statement: The data presented in this study are available on request from the corresponding author A.A.S.

Conflicts of Interest: The authors declare no conflict of interest.

\section{References}

1. Zarone, F.; Di Mauro, M.I.; Ausiello, P.; Ruggiero, G.; Sorrentino, R. Current status on lithium disilicate and zirconia: A narrative review. BMC Oral Health 2019, 19, 1-14. [CrossRef] [PubMed]

2. Anadioti, E.; Aquilino, S.A.; Gratton, D.G.; Holloway, J.A.; Denry, I.L.; Thomas, G.W.; Qian, F. Internal fit of pressed and computer-aided design/computer-aided manufacturing ceramic crowns made from digital and conventional impressions. $J$. Prosthet. Dent. 2015, 113, 304-309. [CrossRef] [PubMed]

3. Fasbinder, D.J.; Dennison, J.B.; Heys, D.; Neiva, G. A Clinical evaluation of chairside lithium disilicate CAD/CAM crowns: A two-year report. J. Am. Dent. Assoc. 2010, 141, 10S-14S. [CrossRef]

4. Valenti, M.; Valenti, A. Retrospective survival analysis of 261 lithium disilicate crowns in a private general practice. Quintessence Int. 2009, 40, 573-579. [PubMed]

5. Sakrana, A.A.; Al-Zordk, W.; El-Sebaey, H.; Elsherbini, A.; Özcan, M. Does Preheating Resin Cements Affect Fracture Resistance of Lithium Disilicate and Zirconia Restorations? Materials 2021, 14, 5603. [CrossRef]

6. Solá-Ruiz, M.F.; Lagos-Flores, E.; Román-Rodriguez, J.L.; Highsmith, J.D.R.; Fons-Font, A.; Granell-Ruiz, M. Survival rates of a lithium disilicate-based core ceramic for three-unit esthetic fixed partial dentures: A 10-Year prospective study. Int. J. Prosthodont. 2013, 26, 175-180. [CrossRef]

7. Miyazaki, T.; Nakamura, T.; Matsumura, H.; Ban, S.; Kobayashi, T. Current status of zirconia restoration. J. Prosthodont. Res. 2013, 57, 236-261. [CrossRef]

8. Brandt, S.; Winter, A.; Lauer, H.-C.; Kollmar, F.; Portscher-Kim, S.-J.; Romanos, G.E. IPS e.max for All-Ceramic Restorations: Clinical Survival and Success Rates of Full-Coverage Crowns and Fixed Partial Dentures. Materials 2019, 12, 462. [CrossRef]

9. Edelhoff, D.; Özcan, M. To what extent does the longevity of fixed dental prostheses depend on the function of the cement? Working Group 4 materials: Cementation. Clin. Oral Implant. Res. 2007, 18, 193-204. [CrossRef]

10. Pegoraro, T.; da Silva, N.R.; Carvalho, R.M. Cements for use in esthetic dentistry. Dent. Clin. N. Am. 2007, 51, 453-471. [CrossRef] [PubMed]

11. Hill, E.E.; Lott, J. A clinically focused discussion of luting materials. Aust. Dent. J. 2011, 56, 67-76. [CrossRef] [PubMed]

12. Perroni, A.P.; Bergoli, C.D.; dos Santos, M.; Moraes, R.R.; Boscato, N. Spectrophotometric analysis of clinical factors related to the color of ceramic restorations: A pilot study. J. Prosthet. Dent. 2017, 118, 611-616. [CrossRef]

13. Ferracane, J.L.; Stansbury, J.W.; Burke, F.J.T. Self-adhesive resin cements-chemistry, properties and clinical considerations. J. Oral Rehabil. 2010, 38, 295-314. [CrossRef]

14. Yang, L.; Chen, B.; Meng, H.; Zhang, H.; He, F.; Xie, H.; Chen, C. Bond durability when applying phosphate ester monomercontaining primers vs. self-adhesive resin cements to zirconia: Evaluation after different aging conditions. J. Prosthodont. Res. 2019, 64, 193-201. [CrossRef] [PubMed]

15. Burgess, J.O.; Ghuman, T.; Cakir, D.; Swift, E.J., Jr. Self-Adhesive resin cements. J. Esthet. Restor. Dent. 2010, 22, 412-419. [CrossRef] [PubMed]

16. Fano, V.; Shatel, M.; Tanzi, M.L. Release phenomena and toxicity in polymer-based dental restorative materials. Acta Biomed. Atenei Parm. 2007, 78, 190-197.

17. Lima, M.O.; Catelan, A.; Marchi, G.M.; Lima, D.A.; Martins, L.R.; Aguiar, F.H. Influence of pre-heating and ceramic thickness on physical properties of luting agents. J. Appl. Biomater. Funct. Mater. 2018, 16, 252-259. [CrossRef]

18. Darabi, F.; Seyed-Monir, A.; Mihandoust, S.; Maleki, D. The effect of preheating of composite resin on its color stability after immersion in tea and coffee solutions: An in-vitro study. J. Clin. Exp. Dent. 2019, 11, e1151-e1156. [CrossRef]

19. Oliveira, M.; Cesar, P.; Giannini, M.; Rueggeberg, F.; Rodrigues, J.; Arrais, C. Effect of temperature on the degree of conversion and working time of dual-cured resin cements exposed to different curing conditions. Oper. Dent. 2012, 37, 370-379. [CrossRef]

20. Goulart, M.; Barbara, B.; Deisi, D.; Glaucia, M.; Fabio, H.; Maria, C. Preheated composite resin used as a luting agent for indirect restorations: Effects on bond strength and resin-dentin interfaces. Int. J. Esthet. Dent. 2018, 13, 86-97.

21. Sakrana, A.A. In vitro evaluation of the marginal and internal discrepancies of different esthetic restorations. J. Appl. Oral Sci. 2013, 21, 575-580. [CrossRef]

22. Su, T.-S.; Sun, J. Comparison of marginal and internal fit of 3-unit ceramic fixed dental prostheses made with either a conventional or digital impression. J. Prosthet. Dent. 2016, 116, 362-367. [CrossRef]

23. Yildiz, C.; Vanlioğlu, B.A.; Evren, B.; Uludamar, A.; Özkan, Y.K. Marginal-internal adaptation and fracture resistance of CAD/CAM crown restorations. Dent. Mater. J. 2013, 32, 42-47. [CrossRef] 
24. Faot, F.; Suzuki, D.; Senna, P.M.; da Silva, W.J.; Sartori, I. Discrepancies in marginal and internal fits for different metal and alumina infrastructures cemented on implant abutments. Eur. J. Oral Sci. 2015, 123, 215-219. [CrossRef]

25. Guess, P.C.; Vagkopoulou, T.; Zhang, Y.; Wolkewitz, M.; Strub, J.R. Marginal and internal fit of heat pressed versus CAD/CAM fabricated all-ceramic onlays after exposure to thermo-mechanical fatigue. J. Dent. 2013, 42, 199-209. [CrossRef]

26. Riccitiello, F.; Amato, M.; Leone, R.; Spagnuolo, G.; Sorrentino, R. In vitro evaluation of the marginal fit and internal adaptation of zirconia and lithium disilicate single crowns: Micro-ct comparison between different manufacturing procedures. Open Dent. J. 2018, 12, 160-172. [CrossRef] [PubMed]

27. Adel, F.; Sattar, J. A comparison of vertical marginal fit of three different types of all ceramic crown restorations (An in vitro study). J. Genet. Environ. Resour. Conser. 2015, 3, 84-92.

28. Anami, L.C.; Pereira, C.A.; Guerra, E.; Souza, R.O.D.A.E.; Jorge, A.O.C.; Bottino, M.A. Morphology and bacterial colonisation of tooth/ceramic restoration interface after different cement excess removal techniques. J. Dent. 2012, 40, 742-749. [CrossRef]

29. Sorensen, J.A. A standardized method for determination of crown margin fidelity. J. Prosthet. Dent. 1990, 64, 18-24. [CrossRef]

30. Darwish, H.A.; Morsi, T.S.; El Dimeery, A.G. Internal fit of lithium disilicate and resin nano-ceramic endocrowns with different preparation designs. Futur. Dent. J. 2017, 3, 67-72. [CrossRef]

31. Kasem, A.T.; Sakrana, A.A.; Ellayeh, M.; Özcan, M. Evaluation of zirconia and zirconia-reinforced glass ceramic systems fabricated for minimal invasive preparations using a novel standardization method. J. Esthet. Restor. Dent. 2020, 32, 560-568. [CrossRef]

32. Bergamo, E.; Bordin, D.; Ramalho, I.S.; Lopes, A.; Gomes, R.S.; Kaizer, M.; Witek, L.; Bonfante, E.A.; Coelho, P.G.; Cury, A.A.D.B. Zirconia-reinforced lithium silicate crowns: Effect of thickness on survival and failure mode. Dent. Mater. 2019, 35, $1007-1016$. [CrossRef]

33. Alraheam, I.A.; Donovan, T.; Boushell, L.; Cook, R.; Ritter, A.V.; Sulaiman, T.A. Fracture load of two thicknesses of different zirconia types after fatiguing and thermocycling. J. Prosthet. Dent. 2020, 123, 635-640. [CrossRef] [PubMed]

34. Potočnik, B. Automated landmark points detection by using a mixture of approaches: The vole-teeth case. Signal. Image Video Process. 2012, 9, 93-104. [CrossRef]

35. Turp, V.; Turkoglu, P.; Sen, D. Influence of monolithic lithium disilicate and zirconia thickness on polymerization efficiency of dual-cure resin cements. J. Esthet. Restor. Dent. 2018, 30, 360-368. [CrossRef] [PubMed]

36. Friedman, G. Thermally assisted flow and polymerization of composite resins. Contemp. Esthet. Restor. Pract. $2003,2,46-52$.

37. Faria-E-Silva, A.L.; Pfeifer, C.S. Development of dual-cured resin cements with long working time, high conversion in absence of light and reduced polymerization stress. Dent. Mater. 2020, 36, e293-e301. [CrossRef]

38. Stegall, D.; Tantbirojn, D.; Perdigão, J.; Versluis, A. Does tack curing luting cements affect the final cure? J. Adhes. Dent. 2017, 19, 239-243. [CrossRef]

39. Flury, S.; Peutzfeldt, A.; Lussi, A. The effect of polymerization procedure on Vickers hardness of dual-curing resin cements. Am. J. Dent. 2011, 24, 226-232.

40. Baig, M.R.; Tan, K.B.C.; Nicholls, J.I. Evaluation of the marginal fit of a zirconia ceramic computer-aided machined (CAM) crown system. J. Prosthet. Dent. 2010, 104, 216-227. [CrossRef]

41. Borges, G.A.; Faria, J.S.; Agarwal, P.; Spohr, A.M.; Correr-Sobrinho, L.; Miranzi, B.A.S. In vitro marginal fit of three all-ceramic crown systems before and after cementation. Oper. Dent. 2012, 37, 641-649. [CrossRef]

42. Subasi, G.; Ozturk, N.; Enan, O.; Bozugllari, N. Evaluation of marginal fit of two all-ceramic copings with two finish lines. Eur. J. Dent. 2012, 6, 163-168.

43. Turgut, S.; Bagis, B. Colour stability of laminate veneers: An in vitro study. J. Dent. 2011, 39, e57-e64. [CrossRef] [PubMed]

44. Mazzitelli, C.; Monticelli, F.; Toledano, M.; Ferrari, M.; Osorio, R. Effect of thermal cycling on the bond strength of self-adhesive cements to fiber posts. Clin. Oral Investig. 2011, 16, 909-915. [CrossRef] [PubMed]

45. El-Dessouky, R.; Salama, M.; Shakal, M.; Korsel, A. Marginal adaptation of CAD/CAM zirconia-based crown during fabrication steps. Tanta Dent. J. 2015, 12, 81-88. [CrossRef]

46. Zeller, S.; Guichet, D.; Kontogiorgos, E.; Nagy, W.W. Accuracy of three digital workflows for implant abutment and crown fabrication using a digital measuring technique. J. Prosthet. Dent. 2019, 121, 276-284. [CrossRef]

47. Peters, B.C.; Cook, R.; Donovan, T.; Sulaiman, T.A. Microcomputed tomography void analysis after cement cleanup methods. J. Prosthet. Dent. 2021. [CrossRef]

48. Elsayad, I. Cuspal Movement and Gap Formation in Premolars Restored with Preheated Resin Composite. Oper. Dent. 2009, 34, 725-731. [CrossRef]

49. Aygün Emiroğlu, Ş.; Evren, B.; Özkan, Y.K. Effect of cements at different temperatures on the clinical performance and marginal adaptation of inlay-onlay restorations in vivo. J. Prosthodont. 2015, 25, 302-309. [CrossRef]

50. Tammam, R. Investigation the effect of restorations fabricated with cad/cam technology, the heat-press technique, and type of resin cement on marginal and internal adaptation of all ceramic crowns. Egypt. Dent. J. 2017, 63, 1627-1639. [CrossRef]

51. Bönecker-Valverde, G.; Maniglia-Ferreira, C.; Abi-Rached, G.P.; Gomes, B.P.; Mesquita, M.F. Seal capability of interim post and core crown with temporary cements. Braz. Oral Res. 2010, 24, 238-244. [CrossRef] [PubMed]

52. Albert, F.; El-Mowafy, O. Marginal adaptation and microleakage of Procera All Ceram crowns with four cements. Int. J. Prosthet. Dent. 2004, 17, 529-535. [CrossRef]

53. Borba, M.; Cesarc, P.F.; Griggs, J.A.; Della Bona, Á. Adaptation of all-ceramic fixed partial dentures. Dent. Mater. 2011, 27, 1119-1126. [CrossRef] [PubMed] 